BMJ Open

Diabetes

Research

\& Care

\title{
Ethnic variation in the conversion of prediabetes to diabetes among immigrant populations relative to Canadian-born residents: a population- based cohort study
}

\author{
Ghazal S Fazli (10 , ${ }^{1,2}$ Rahim Moineddin, ${ }^{3}$ Arlene S Bierman, ${ }^{2}$ Gillian L Booth ${ }^{1,2,4,5}$
}

To cite: Fazli GS, Moineddin R, Bierman AS, et al. Ethnic variation in the conversion of prediabetes to diabetes among immigrant populations relative to Canadian-born residents: a population-based cohort study. BMJ Open Diab Res Care 2020;8:e000907. doi:10.1136/ bmjdrc-2019-000907

\section{- Additional material is} published online only. To view please visit the journal online (http://dx.doi.org/10.1136/ bmjdrc-2019-000907).

Received 13 September 2019 Revised 21 November 2019 Accepted 20 December 2019

Check for updates

\section{(c) Author(s) (or their} employer(s)) 2020. Re-use permitted under CC BY-NC. No commercial re-use. See rights and permissions. Published by BMJ.

For numbered affiliations see end of article.

Correspondence to Dr Ghazal S Fazli; ghazal.fazli@utoronto.ca

\section{ABSTRACT}

Objective The aim of this study was to compare absolute and relative rates of conversion from prediabetes to diabetes among non-European immigrants to Europeans and Canadian-born residents, overall, and by age and level of glycemia.

Research design and methods We conducted a retrospective cohort population-based study using administrative health databases from Ontario, Canada, to identify immigrants $(n=23465)$ and Canadian born $(n=111085)$ aged $\geq 20$ years with prediabetes based on laboratory tests conducted between 2002 and 2011. Individuals were followed until 31 December 2013 for the development of diabetes using a validated algorithm. Immigration data was used to assign ethnicity based on country of origin, mother tongue, and surname. Fine and Gray's survival models were used to compare diabetes incidence across ethnic groups overall and by age and glucose category.

Results Over a median follow-up of 5.2 years, 8186 immigrants and 39722 Canadian-born residents developed diabetes (7.1 vs 6.1 per 100 person-years, respectively). High-risk immigrant populations such as South Asians (HR: $1.72,95 \% \mathrm{Cl} 1.55$ to 1.99) and Southeast Asians (HR: $1.65,95 \% \mathrm{Cl} 1.46$ to 1.86 ) had highest risk of converting to diabetes compared with Western Europeans (referent). Among immigrants aged 20-34 years, the adjusted cumulative incidence ranged from $18.4 \%$ among Eastern Europeans to $52.3 \%$ among Southeast Asians. Conversion rates increased with age in all groups but were consistently high among South Asians, Southeast Asians and Sub-Saharan African/Caribbeans after the age of 35 years. On average, South Asians converted to diabetes 3.1-4.6 years earlier than Western Europeans and at an equivalent rate of conversion to Western Europeans who had a $0.5 \mathrm{mmol} / \mathrm{L}$ higher baseline fasting glucose value. Conclusions High-risk ethnic groups converted to diabetes more rapidly, at younger ages, and at lower fasting glucose values than European populations, leading to a shorter window for diabetes prevention.

\section{INTRODUCTION}

Diabetes is one of the fastest growing epidemics worldwide. Widespread shifts in

\section{Significance of this study}

What is already known about this subject?

> Studies suggest that $5 \%-15 \%$ of individuals with prediabetes will develop type 2 diabetes each year, depending on their ethnicity, the type of glucose abnormality, and threshold used to define prediabetes.

- Although studies conducted in non-European populations report higher rates of conversion from prediabetes to diabetes than those conducted in European populations, direct comparisons between a broad range of ethnic groups are lacking.

What are the new findings?

- Findings revealed that prediabetes confers a different prognosis depending on ethnicity, age, and level of glycemia. In particular, non-Europeans with prediabetes converted to diabetes up to 4.6 years earlier than Western Europeans.

How might these results change the focus of research or clinical practice?

- This study suggests that the window in which to implement type 2 diabetes prevention strategies is far shorter in non-European populations compared with Europeans of the same age and level of glycemia. Further consideration should be given for commencing diabetes screening earlier and at lower levels of glycemia in high-risk ethnic groups.

lifestyle and aging of the world's populations have resulted in an unprecedented rise in the global prevalence of diabetes and its complications. ${ }^{12}$ In recent decades, rapid shifts in urbanization caused by economic growth and rural to urban migration have fueled rising rates of diabetes in low-income and middle-income countries by increasing access to unhealthy food options and reducing the opportunities local residents have for physical activity. ${ }^{1-4}$ According to the International Diabetes Federation, 693 million people are expected to have diabetes by 2045 , with the 
largest increases expected in India and China. ${ }^{3}$ Based on current estimates, diabetes prevalence is highest in regions within the Western Pacific, Middle East, North Africa and Central America, with some countries reporting a prevalence of $15 \%-20 \%$ or higher among adults aged $20-79$ years. ${ }^{3}$

Ethnicity is an important factor influencing the risk of metabolic disease. Approximately 5\%-15\% of people with prediabetes convert to diabetes each year depending on the underlying characteristics of the population (eg, ethnicity) and the type and severity of their glucose abnormality. ${ }^{5-15}$ The landmark US Diabetes Prevention Program (DPP) reported diabetes incidence among participants who were enrolled in the placebo arm, finding $25 \%$ higher rates among African-American, Hispanic, American Indian and Asian participants than non-Hispanic whites. ${ }^{5}$ Several other studies have demonstrated high rates of conversion within specific ethnic populations including Chinese, Japanese, European and South Asians, among others, even after accounting for individual and socioeconomic factors. ${ }^{5-15}$ However, comparisons across a broader range of ethnicities is lacking.

There is mounting evidence that intensive lifestyle interventions can substantially reduce the rate of conversion from prediabetes to diabetes. Clinical practice guidelines recommend earlier and more frequent screening for diabetes in high-risk populations, including those of non-European heritage, to avoid missed opportunities for diabetes prevention. However, it is unclear whether the window to incorporate diabetes prevention strategies is similar across ethnic groups in whom a diagnosis of prediabetes has been made.

The primary aim of this study was to examine the absolute and relative risk of conversion from prediabetes to type 2 diabetes in non-European ethnic groups relative to Europeans and Canadian-born residents of the same age. The secondary aim of this study was to derive a similar follow-up time and level of glycemia among non-Europeans that conferred an equivalent probability of converting to type 2 diabetes as Western Europeans. We hypothesized that nonEuropean populations, particularly South Asians, would have a substantially higher risk of converting to diabetes than that of Europeans and that compared with the latter, non-Europeans would convert to diabetes more rapidly, at younger ages, and at lower levels of glycemia.

\section{METHODS}

\section{Study design and population}

We used population-level health and laboratory data from Ontario, Canada, to identify adults who were found to have prediabetes on laboratory testing between 2002 and 2011. Individuals were then followed until 31 December 2013 for the development of diabetes. Our primary population of interest were immigrants to Canada because information on ethnicity was available through federal immigration data for those having immigrated since 1985 . We also ascertained data on long-term residents with prediabetes who did not meet this criteria. This comparison population largely included individuals who were Canadian born and those who immigrated to Canada prior to 1985 (referred to herein as 'Canadian born'). Nearly $30 \%$ of Ontario's current residents were born outside of Canada, enabling us to assemble a large multiethnic cohort of adults with prediabetes and to follow their health outcomes over time. Canada's healthcare system is designed to provide universal and comprehensive coverage of healthcare services to all permanent residents. As such, Ontario's administrative healthcare data capture service utilization and outcomes for all permanent residents regardless of whether they are Canadian born or landed immigrants. For this study, we combined a variety of health and non-healthcare datasets, including detailed records at the time of immigration. Records were linked across databases using unique, encoded identifiers and analyzed at ICES, a research institute affiliated with the University of Toronto.

The study included data on all adults, aged 20-85 years, who met the case definition of prediabetes based on glucose tests performed between 1 January 2002 and 31 December 2011 at one of the province's 225 Dynacare Medical Laboratory (DML) locations. DML is one of the largest commercial laboratories in Ontario, performing $25 \%-30 \%$ of all glucose tests ordered by Ontario doctors. These are directly reimbursed through the province's healthcare system, and prior research suggests that the demographic characteristics of individuals who are tested through DML are similar to those tested elsewhere. ${ }^{16}$

Prediabetes was defined as impaired fasting glucose (IFG; $6.1-6.9 \mathrm{mmol} / \mathrm{L}$ ), impaired glucose tolerance (IGT; 2-hour glucose of $7.8-11.0 \mathrm{mmol} / \mathrm{L}$ after a $75 \mathrm{~g}$ oral glucose tolerance test (OGTT) or glycosylated hemoglobin $\left(\mathrm{HbAl}_{\mathrm{c}}\right)$ of $6.0 \%-6.4 \%$ using criteria established by the WHO and Diabetes Canada. ${ }^{17}$ A 2-year look-back window was set to ensure that individuals did not have blood glucose values in the diabetes range prior to meeting the case definition for prediabetes.

\section{Measures}

Ethnicity and immigration status were the main exposures in this study. The Immigration, Refugees and Citizenship Canada Permanent Resident (IRCC-PR) database was used to classify people who landed in Canada after 1985 as immigrants. All others were classified as Canadian-born residents. Among immigrants, a validated algorithm was used to derive ethnic groups based on country of birth, mother tongue, and surnames. ${ }^{18} 19$ As a result, people of different ethnic origins were classified into the following groups: Eastern European, Western European, Latin American, sub-Saharan African and Caribbean, West Asian and Arab, East Asian, Southeast Asian, and South Asian (online supplementary table 1). Immigration-related information such as country of birth, mother tongue, education level, immigration visa category, marital status, landing date and English language proficiency was obtained from the IRCC-PR dataset. Demographic and vital statistics information was obtained from Ontario's Registered Persons 
Database (RPDB). The IRCC-PR and the RPDB have been probabilistically linked with a linkage rate of $86.4 \% .{ }^{20}$ Since information on individual income was not available for our cohort, neighborhood-level income quintiles were assigned instead using information collected in the 2006 Canadian Census. These values were based on small geographical units defined by Statistics Canada, dissemination areas, and adjusted for household and community size. Dissemination areas consist of one or more city blocks and a population size of 400-700 persons.

Individuals were followed for a minimum of 2 years until 31 December 2013 to identify new diabetes cases using the Ontario Diabetes Database (ODD). The ODD uses a validated algorithm based on hospitalization and physicians' services claims data to identify individuals with diabetes (excluding those with gestational diabetes) and has a sensitivity of $89 \%$ and a specificity of over $98 \% .^{21}$ Individuals with a record in the ODD or with any diabetes-range glucose measures in DML prior to baseline were excluded from the study cohort.

\section{Statistical analyses}

Crude diabetes incidence rates were calculated per 100 person-years with the number of people who developed diabetes on follow-up as the numerator and total personyears as the denominator. Unadjusted and adjusted cumulative incidence function curves for diabetes incidence were generated for immigrants of different ethnic origins using Fine and Gray's survival modeling. ${ }^{22}$ Using Fine and Gray's cumulative incidence function with competing risks allowed us to estimate the incidence of diabetes in the presence of a competing event. In this case, death was treated as a competing event in all analyses. In addition, individuals were censored if they lost healthcare coverage (indicating a move out of province). Also, the proportionality of hazards assumption was assessed using log-negative-log of the Kaplan-Meier survival curves against the log of survival time. Also, the assumption of linearity was assessed for continuous variables such as age. All assumptions were met for all covariates in the models.

Among immigrants, we compared the incidence of diabetes in each ethnic group relative to Western Europeans (referent population), adjusting for age and sex. Next, we generated fully adjusted models accounting for additional covariates including area income, education, immigration visa category, marital status, and duration in Canada. We conducted stratified analyses by age group and sex to compare the effects of ethnicity on diabetes incidence across these groups. Similar analyses were conducted to compare the risk of conversion to diabetes among immigrants (all ethnicities combined) and Canadian-born residents with prediabetes at baseline.

As a secondary analysis, we compared the rate of conversion from prediabetes to diabetes among immigrants in each ethnic group using three different thresholds of impaired fasting glucose to define prediabetes. The categories included fasting values of: (1) $5.7-6.0 \mathrm{mmol} / \mathrm{L}$, (2) $6.1-6.5 \mathrm{mmol} / \mathrm{L}$, and (3) fasting $6.6-6.9 \mathrm{mmol} / \mathrm{L}$.
Virtually all individuals in our cohort had fasting glucose measurements on or near the index date and few had baseline HbA1 $1_{c}$ or an OGTT performed; therefore, only fasting glucose values were considered in assigning these categories. As above, the cumulative incidence rates were also adjusted for sociodemographic and immigration factors.

In addition, we used cumulative incidence function curves to plot the relation between follow-up time (x) and cumulative incidence probability for the development of diabetes (y). We then used a line of best fit based on a polynomial (quadratic) equation $\left(\mathrm{y}=\mathrm{a}+\mathrm{bx}+\mathrm{cx}^{2}\right)$ to derive the follow-up time in years $(\mathrm{x})$ from baseline that corresponded to a cumulative incidence probability (y) of 0.25 or 0.50 (ie, the time required for $25 \%-50 \%$ of the population to develop diabetes). We used a cumulative incidence probability threshold of 0.25 to compare ethnic groups that had baseline fasting glucose concentrations between 6.1 and $6.5 \mathrm{mmol} / \mathrm{L}$, as the overall incidence of diabetes was lower in this group, and a cumulative incidence probability threshold of 0.50 to compare ethnic groups that had baseline fasting glucose concentrations between $6.6 \mathrm{mmol} / \mathrm{L}$ and $6.9 \mathrm{mmol} / \mathrm{L}$, as this group had a higher incidence of diabetes. Differences in follow-up time in years were calculated by subtracting the value obtained (above) for each ethnic group from that derived for Western Europeans (the referent population).

Lastly, we ran additional models to examine whether there was an interaction between ethnicity and duration in Canada (for immigrants only) to test for any modifying effects of the amount of time spent in Canada on the conversion to diabetes.

All analyses were conducted using an alpha level of 0.05 and by using SAS Enterprise, V.7.4.

\section{RESULTS}

Overall, there were 23465 immigrants and 111085 Canadian-born residents with prediabetes in our cohort. Baseline characteristics of the study population by immigration status and ethnicity are shown in table 1 and online supplementary table 2 . Briefly, immigrants were younger at baseline compared with Canadian-born residents (mean age 49.9 vs 57.1, respectively) and more likely to live in lower income neighborhoods (table 1). More than half of immigrants arrived to Canada with high school education attainment or less, with the exception of Eastern Europeans. Although the majority of immigrant populations landed with an economic visa that includes skilled workers and their family members, a larger proportion of immigrants of sub-Saharan African/Caribbean, Latin American, and West Asians/Arab descent arrived to Canada with a refugee status (online supplementary table 2).

The median follow-up time was 5.2 years, and over this period 8186 immigrants and 39722 Canadian-born residents progressed from prediabetes to diabetes, respectively. Compared with the latter, the crude incidence of 
Table 1 Characteristics of study population at baseline by immigration status $(n=134550)$

\begin{tabular}{lll}
\hline & $\begin{array}{l}\text { Canadian-born } \\
\text { residents } \\
\mathbf{n}=\mathbf{1 1 1 0 8 5}\end{array}$ & $\begin{array}{l}\text { Immigrants } \\
\mathbf{n}=\mathbf{2 3 4 6 5}\end{array}$ \\
\hline Variables & $57.1 \pm 12.9$ & $49.9 \pm 12.8$ \\
\hline Mean age $\pm \mathrm{SD}^{*}$ & 42.7 & 43.8 \\
\hline Females & & \\
\hline Income quintile $\dagger$ & 16.7 & 28.7 \\
\hline Q1 (lowest) & 20.1 & 23.9 \\
\hline Q2 & 20.7 & 20.2 \\
\hline Q3 & 21.0 & 17.3 \\
\hline Q4 & 21.4 & 10.0 \\
\hline Q5 (highest) & 79.6 & 62.2 \\
\hline Prediabetes criteria met at baseline for the entire population & 1.30 \\
\hline IFG of 6.1-6.9 mmol/L & 79.91 & 36.7 \\
\hline IGT of $7.8-11.0 \mathrm{mmol} / \mathrm{L}$ & 19.5 & \\
\hline HbA1 ${ }_{\mathrm{c}}$ of $6.0 \%-6.4 \%$ &
\end{tabular}

All values expressed as \% unless otherwise specified.

*Demographic information was obtained from Ontario's

Registered Persons Database.

†Neighborhood income quintiles were derived from the 2006

Canadian census and adjusted for household and community size.

HbA1, glycosylated hemoglobin; IFG, impaired fasting glucose; IGT, impaired glucose tolerance.

diabetes was higher among immigrants (7.1 vs 6.1 per 100 person-years) (table 2).

Over the 12-year follow-up period, the adjusted cumulative incidence of diabetes was substantially higher among non-European immigrants compared with Western
Europeans (40.8\%, referent), ranging from $56.3 \%$ to $59.3 \%$ for sub-Saharan African/Caribbeans (adjusted HR: $1.63,95 \%$ CI 1.45 to 1.83), Southeast Asians (adjusted HR: $1.65,95 \%$ CI 1.46 to 1.86 ), and South Asians (adjusted HR: $1.72,95 \%$ CI 1.55 to 1.99 ) (table 2). These ethnic differences were also apparent among younger adults. Over 12 years, nearly $50 \%$ of South Asians and Southeast Asians aged 20-34 converted to diabetes (figure 1). The incidence of diabetes rose further with increasing age reaching a cumulative conversion rate of nearly $60 \%$ for adults of South Asian, Southeast Asian, West Asian and Arab, and Sub-Saharan African and Caribbean origins at the age of 35 years and older. For other ethnic groups, such as Latin Americans, the risk of converting to diabetes approached $60 \%$ after age 65 years.

Over the study period, the adjusted cumulative incidence of diabetes was increased with higher levels of fasting plasma glucose at baseline. However, ethnic differences in diabetes incidence persisted regardless of baseline glycemia (online supplementary figure 1). Nonetheless, non-Europeans converted to diabetes 3.1-4.6 years earlier than European populations (figure 2).

Adjusted conversion rates among non-Europeans were similar to that of Europeans who had higher levels of glycemia at baseline. For example, the cumulative incidence of diabetes among South Asians who had baseline fasting glucose values of $6.1-6.5 \mathrm{mmol} / \mathrm{L}$ was equivalent to that of Western Europeans who had baseline fasting glucose values of $6.6-6.9 \mathrm{mmol} / \mathrm{L}$. In both instances, $\sim 60 \%$ of individuals developed diabetes over the study period (figure 3 ). At lower baseline fasting glucose values of $5.7-6.0 \mathrm{mmol} / \mathrm{L}$,

Table 2 Association between ethnicity/immigration status and diabetes incidence $(n=134550)$

\begin{tabular}{|c|c|c|c|c|c|}
\hline Variable & $\begin{array}{l}\text { No. new } \\
\text { cases of } \\
\text { diabetes }^{*}\end{array}$ & $\begin{array}{l}\text { Person-years of } \\
\text { follow-up }\end{array}$ & $\begin{array}{l}\text { Crude incidence } \\
\text { (no./100 person-years) }\end{array}$ & $\begin{array}{l}\text { Age, sex- adjusted } \\
\text { HR }(95 \% \mathrm{Cl})^{\star} \dagger\end{array}$ & $\begin{array}{l}\text { Fully adjusted HR } \\
(95 \% \mathrm{Cl})^{\star} \ddagger\end{array}$ \\
\hline \multicolumn{6}{|l|}{ Immigrants, ethnicity§ } \\
\hline South Asian & 2417 & 28597 & 8.5 & 1.71 (1.55 to 1.89$)$ & 1.72 (1.55 to 1.99$)$ \\
\hline Southeast Asian & 916 & 11492 & 8.0 & $1.58(1.41$ to 1.77$)$ & 1.65 (1.46 to 1.86$)$ \\
\hline $\begin{array}{l}\text { Sub-Saharan African and } \\
\text { Caribbean }\end{array}$ & 890 & 11780 & 7.6 & 1.55 (1.39 to 1.74$)$ & 1.63 (1.45 to 1.83$)$ \\
\hline Latin American & 702 & 9506 & 7.4 & 1.49 (1.32 to 1.68$)$ & 1.58 (1.41 to 1.78$)$ \\
\hline East Asian & 1270 & 18119 & 7.0 & 1.34 (1.23 to 1.52$)$ & $1.53(1.35$ to 1.73$)$ \\
\hline West Asian and Arab & 756 & 9271 & 8.2 & $1.63(1.45$ to 1.84$)$ & 1.37 (1.23 to 1.53$)$ \\
\hline Eastern European & 769 & 16710 & 4.6 & $0.92(0.82$ to 1.03$)$ & 0.92 (0.82 to 1.04$)$ \\
\hline Western European & 466 & 9510 & 4.9 & Referent & Referent \\
\hline \multicolumn{6}{|c|}{ Entire cohort, immigration status } \\
\hline Immigrants to Canada & 8186 & 649828 & 7.1 & 1.18 (1.15 to 1.20$)$ & 1.15 (1.12 to 1.18$)$ \\
\hline Canadian-born residents & 39722 & 115043 & 6.1 & Referent & - \\
\hline
\end{tabular}

*New cases of diabetes were determined based on entry into the Ontario Diabetes Database. Cases censored at time when diabetes was ascertained, lost healthcare coverage, died or 31 December 2013.

†Adjusted for age, sex, and area income.

†Among immigrants only, adjusted for age, sex, area income, education, ethnicity, marital status, immigration visa category, and duration. These covariates were not available for the Canadian-born residents.

§Ethnic groups were derived based on country of birth, mother tongue, and a validated algorithm that identifies ethnic groups based on surnames for South Asian and Chinese populations only. 

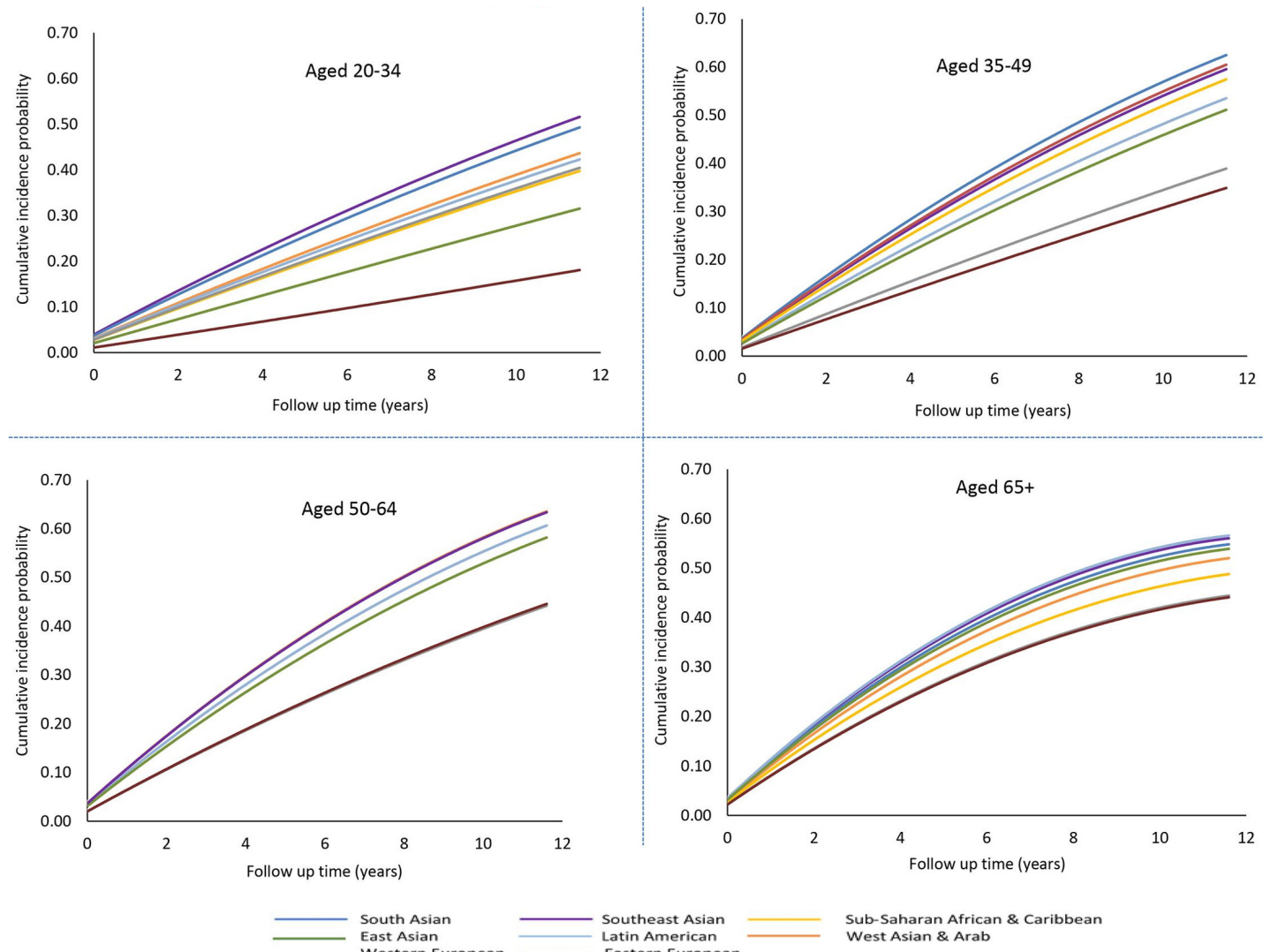

Sub-Saharan African \& Caribbean Eastern Europe

Figure 1 Adjusted cumulative incidence function for diabetes among immigrants, by ethnicity and age groups. Adjusted for age, sex, ethnicity, area income, education, marital status, immigration visa category, and duration. New cases of diabetes were determined based on entry into the Ontario Diabetes Database. Cases censored at time when diabetes was ascertained, lost health care coverage, died, or 31 December 2013. All lines based on line of best fit using a polynomial equation, $R^{2}>0.99$ for each.

the rate of conversion was $27 \%$ among South Asians and $12 \%$ among Western Europeans (online supplementary figure 1). Similar findings were apparent for other highrisk non-European groups (data not shown).

Overall, ethnic disparities were consistent across sexes, and in some high-risk ethnic groups, these effects were stronger for men (online supplementary figure 2). Also, duration in Canada modified the relationship between ethnicity and conversion to diabetes such that ethnic disparities that were evident in the first 10 years of living in Canada were more accentuated with greater time $(>10$ years) since landing (online supplementary figure 3).

\section{DISCUSSION}

In this study, rates of conversion from prediabetes to diabetes were substantially higher among non-European immigrants to Canada than Europeans regardless of their age, sex, and level of glycemia. Relative to Western Europeans, individuals of South Asian, Southeast Asian, and subSaharan African/Caribbean descent had one and a half to twofold higher adjusted conversion rates, with $\sim 60 \%$ developing diabetes over 12 years. Moreover, these ethnic differences emerged at young ages. One in two South Asians and Southeast Asians with prediabetes who were between the ages of 20 years and 34 years converted to diabetes over this same period. These higher risk populations also bear an increased incidence of prediabetes, adding to their growing burden of type 2 diabetes in middle age. ${ }^{23}$ Our findings suggest that a single definition of prediabetes confers a different prognosis depending on the ethnicity of the population. Moreover, non-Europeans with prediabetes developed diabetes years earlier than Europeans with the same level of glycemia, suggesting that the window to adopt intensive lifestyle strategies is much shorter for highrisk ethnic groups.

This research adds to previous literature examining the rate of conversion from prediabetes to diabetes in various populations. ${ }^{5-15}$ However, our study was the first to provide a detailed analysis of this phenomenon in a large multiethnic sample, allowing for a comparison of conversion rates across immigrants from various world regions. Similar to other studies that have demonstrated a higher prevalence of diabetes among individuals of South Asian heritage, ${ }^{24} 25$ we found much higher rates of conversion to diabetes in South Asian immigrants with prediabetes compared with those of European descent. In this study, the crude incidence of diabetes among South Asians and Southeast Asians (8.6 and 8.0 per 100 person-years, respectively) was comparable with rates reported for Pima Indians and Asian Indians but higher than those reported 


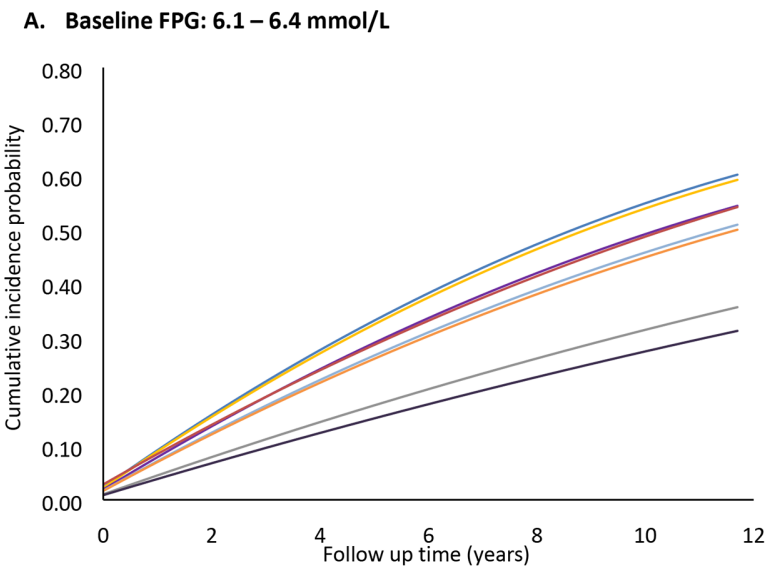

\begin{tabular}{|l|c|c|}
\hline Ethnic Group & $\begin{array}{c}\text { Time (years) until } \\
\text { cumulative incidence } \\
\text { probability of } 0.25\end{array}$ & $\begin{array}{c}\text { Difference (years) } \\
\text { from Western } \\
\text { Europeans }\end{array}$ \\
\hline South Asian & 3.5 & 4.2 \\
\hline Southeast Asian & 4.2 & 3.5 \\
\hline $\begin{array}{l}\text { Sub-Saharan } \\
\text { African/Caribbean }\end{array}$ & 3.6 & 4.1 \\
\hline Latin American & 4.6 & 3.1 \\
\hline West Asian/Arab & 4.3 & 3.5 \\
\hline East Asian & 4.7 & 3 \\
\hline Eastern European & 9.1 & -1.4 \\
\hline $\begin{array}{l}\text { Western European } \\
\text { (referent) }\end{array}$ & 7.7 & 0 \\
\hline
\end{tabular}

B. Baseline FPG: $6.5-6.9 \mathrm{mmol} / \mathrm{L}$

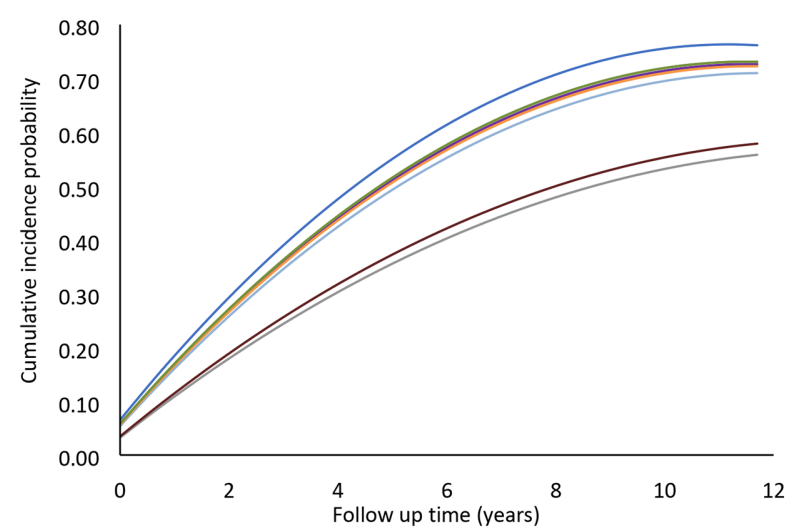

\begin{tabular}{|l|c|c|}
\hline Ethnic Group & $\begin{array}{c}\text { Time (years) until } \\
\text { cumulative incidence } \\
\text { probability of } 0.50\end{array}$ & $\begin{array}{c}\text { Difference (years) } \\
\text { from Western } \\
\text { Europeans }\end{array}$ \\
\hline South Asian & 4.3 & 4.6 \\
\hline Southeast Asian & 4.9 & 4.0 \\
\hline $\begin{array}{l}\text { Sub-Saharan } \\
\text { African/Caribbean }\end{array}$ & 4.9 & 4.0 \\
\hline Latin American & 5.1 & 3.8 \\
\hline West Asian/Arab & 4.9 & 4.0 \\
\hline East Asian & 4.8 & 4.1 \\
\hline Eastern European & 8.0 & 0.9 \\
\hline $\begin{array}{l}\text { Western European } \\
\text { (referent) }\end{array}$ & 8.9 & 0 \\
\hline
\end{tabular}

South Asian
East Asian

Southeast Asian Latin American

Sub-Saharan African \& Caribbean

Western Europe

Sub-Saharan African \&
West Asian \& Arab

Figure 2 Adjusted a cumulative incidence of diabetes among immigrants, by fasting glucose category at baseline. Adjusted for age, sex, ethnicity, area income, education, marital status, immigration visa category, and duration. New cases of diabetes were determined based on entry into the Ontario Diabetes Database. Cases censored at time when diabetes was ascertained, lost health care coverage, died, or 31 December 2013. All lines based on line of best fit using a polynomial equation, $R^{2}>0.99$ for each.

for Native Americans, in general, and Europeans living in Denmark and Spain. ${ }^{11-14}$

The risk of diabetes among immigrants may be shaped, in part, by socioeconomic, environmental, and political influences that lead to immigration and acculturation to post immigration life. A significant proportion of immigrants in our study lived in lower income neighborhoods, a factor that was independently associated with a higher risk of diabetes. Furthermore, high-risk immigrant groups may be more likely to live in suburban neighborhoods that offer fewer opportunities for physical activity. ${ }^{26}$ Although we adjusted for some of these factors, it is difficult to disentangle environmental influences from cultural or genetic ones. As a result, in high-risk immigrant groups, a constellation of factors may drive the risk of conversion to diabetes, including smoking behaviors, food insecurity, sedentary lifestyles, poorer working conditions, limited community empowerment, social isolation, and other socioeconomic and environmental stressors. ${ }^{27}$

Furthermore, numerous migrant studies have shown an association between acculturation to a western lifestyle and the likelihood of developing diabetes and other metabolic diseases, with observed declines in immigrants' health with increasing time spent in the host country. ${ }^{25270}$ These findings and others have led to the theory known as the healthy migrant phenomena. In line with this concept, ethnic differences in the rate of conversion from prediabetes to diabetes in our study were greater among populations who had been in Canada more than 10 years. Differences in acculturation to a western lifestyle may contribute to these findings as some studies suggest that immigrant populations that preserve their cultural traditions with respect to diet and physical activity gain less weight and have more favorable metabolic outcomes. ${ }^{3031}$

To our knowledge, this was the first population-based longitudinal cohort analysis comparing the risk of conversion from prediabetes to diabetes across a broad range of ethnic groups living in similar environments. Additionally, access to linked administrative health and immigration data allowed us to study this phenomenon in a large sample and to examine subsets of the population on the basis of age group, age and duration in Canada. However, our study has several limitations. First, although we used validated algorithms to derive ethnic origins, some degree 

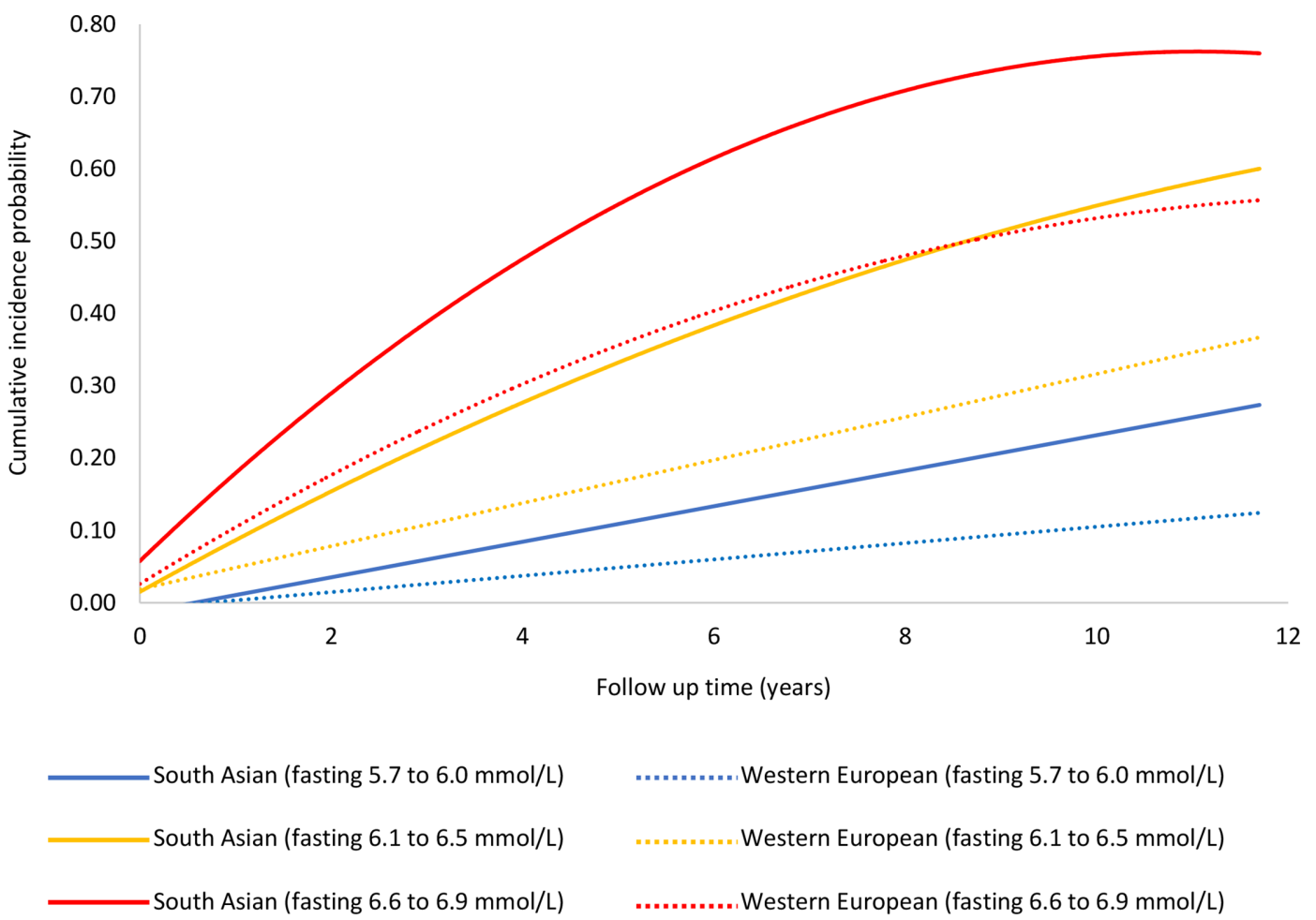

Western European (fasting 5.7 to $6.0 \mathrm{mmol} / \mathrm{L}$ )

. ......... Western European (fasting 6.1 to $6.5 \mathrm{mmol} / \mathrm{L}$ )

............Western European (fasting 6.6 to $6.9 \mathrm{mmol} / \mathrm{L}$ )

Figure 3 Adjusted cumulative incidence function for diabetes among South Asians and Western Europeans, by fasting glucose category. Adjusted for age, sex, ethnicity, area income, education, marital status, immigration visa category and duration. New cases of diabetes were determined based onentry into the Ontario Diabetes Database. Cases censored at time when diabetes was ascertained, lost health care coverage, died, or 31 December 2013. All lines based on line of best fit using a polynomial equation, $R^{2}>0.99$ for each.

of misclassification may have occurred due to the broad categorization of ethnicity based on world regions, since ethnic groups living within a given region may be quite heterogenous. Second, these data sources lacked information on diet and physical activity patterns, health beliefs, body mass index, family history of diabetes and other markers of insulin resistance, as well as premigration risk factors. Thus, causes of the ethnic differences observed in this study could not be fully elucidated. Third, our definition of Canadian-born residents included immigrants who arrived in Canada prior to 1985, which may lead to some degree of misclassification. However, this would tend to reduce differences between immigrants and Canadianborn residents and thus go against our null hypothesis. Fourth, we used a single commercial laboratory for identifying prediabetes cases, which captures approximately one-third of blood tests in Ontario and therefore did not include all true prediabetes cases in our setting, and repeat laboratory testing at a different laboratory would not have been captured. However, we used a validated algorithm to identify new cases of diabetes across the province, which allowed for comprehensive follow-up data for all individuals in our cohort. Fifth, although we did not measure healthcare utilization (ie, primary care visits), there is no evidence that screening rates are lower among immigrants. ${ }^{32}$ Therefore, under Ontario's universal healthcare plan, primary care use and diabetes screening rates are high among Ontarians.
This study has several policy and practice implications for diabetes prevention. The rapid rate of conversion to diabetes among young adults from high-risk ethnic groups is concerning given the lack of specific guidance on how early to screen these populations for prediabetes. There are missed opportunities for diabetes prevention if highrisk groups with prediabetes are left unidentified and a shorter window to prevent diabetes development once a diagnosis of prediabetes is made. Earlier screening strategies and targeted interventions to promote healthier lifestyles in high-risk communities may help to address these challenges. In particular, community-based programs, including those similar to the DPP-translated interventions, that are culturally sensitive may prove to be more effective in reducing the burden of diabetes. ${ }^{33-35}$ Further research is needed to understand the optimal approaches to screening and prevention in order to reduce the burden of diabetes in high-risk populations.

\section{Author affiliations}

${ }^{1}$ MAP- Centre for Urban Health Solutions, Li Ka Shing Knowledge Institute, St. Michael's Hospital, Toronto, Ontario, Canada

${ }^{2}$ Institute of Health Policy Management and Evaluation, University of Toronto, Toronto, Ontario, Canada

${ }^{3}$ Department of Family and Community Medicine, University of Toronto, Toronto, Ontario, Canada

${ }^{4}$ ICES, Toronto, Ontario, Canada

${ }^{5}$ Faculty of Medicine, University of Toronto, Toronto, Ontario, Canada 
Acknowledgements The authors would like to acknowledge Ms Anna Chu and Dr Mohammad-Reza Rezai for their support on gaining access ICES datasets. The authors wish to thank Immigration, Refugees and Citizenship Canada for proving access to data on our immigrant cohort.

Contributors This study was conceptualized and written by GSF and GLB, and RM and ASB helped in design and review of the manuscript.

Funding This work was supported by the Canadian Institute for Health Research (CIHR). GLB is supported by a Clinician Scientist Merit Award from the University of Toronto and received a Heart and Stroke Foundation of Ontario Mid-Career Investigator Award during the tenure of this study. GSF is funded by the CIHR Health Systems Impact Post-Doctoral Fellowship. ASB contributed to this article in her personal capacity. The views expressed are her own and do not necessarily represent the views of the Agency for Healthcare Research and Quality or the United States Government. This study was supported by ICES, which is funded by an annual grant from the Ontario Ministry of Health and Long-Term Care (MOHLTC). Parts of this material are based on data and information compiled and provided by: MOHLTC, Canadian Institute for Health Information and Immigration, Refugees, and Citizenship Canada. The analyses, conclusions, opinions and statements expressed herein are solely those of the authors and do not reflect those of the funding or data sources; no endorsement is intended or should be inferred.

Competing interests None declared.

Patient consent for publication Not required.

Ethics approval This study received ethics approval from the University of Toronto and Institutional Review Board at Sunnybrook Health Sciences Centre.

Provenance and peer review Not commissioned; externally peer reviewed.

Data availability statement The data presented in this study are housed at ICES and are not publicly available due to privacy agreements.

Open access This is an open access article distributed in accordance with the Creative Commons Attribution Non Commercial (CC BY-NC 4.0) license, which permits others to distribute, remix, adapt, build upon this work non-commercially, and license their derivative works on different terms, provided the original work is properly cited, appropriate credit is given, any changes made indicated, and the use is non-commercial. See: http://creativecommons.org/licenses/by-nc/4.0/.

ORCID iD

Ghazal S Fazli http://orcid.org/0000-0002-8157-7762

\section{REFERENCES}

1 Guariguata L, Whiting DR, Hambleton I, et al. Global estimates of diabetes prevalence for 2013 and projections for 2035. Diabetes Res Clin Pract 2014:103:137-49.

$2 \mathrm{Hu}$ FB. Globalization of diabetes: the role of diet, lifestyle, and genes. Diabetes Care 2011;34:1249-57.

3 International Diabetes Federation. Diabetes atlas. 8th ED International Diabetes Federaion, 2017.

4 World Health Organization. Global status report on noncommunicable diseases 2010. World Health Organization, 2010.

5 Knowler WC, Barrett-Connor E, Fowler SE, et al. Reduction in the incidence of type 2 diabetes with lifestyle intervention or metformin. N Engl J Med 2002;346:393-403.

6 Forouhi NG, Luan J, Hennings S, et al. Incidence of type 2 diabetes in England and its association with baseline impaired fasting glucose: the Ely study 1990-2000. Diabet Med 2007;24:200-7.

7 Heianza Y, Hara S, Arase Y, et al. HbA1c 5·7-6.4\% and impaired fasting plasma glucose for diagnosis of prediabetes and risk of progression to diabetes in Japan (TOPICS 3): a longitudinal cohort study. Lancet 2011;378:147-55.

8 Ramachandran A, Snehalatha C, Mary S, et al. The Indian diabetes prevention programme shows that lifestyle modification and metformin prevent type 2 diabetes in Asian Indian subjects with impaired glucose tolerance (IDPP-1). Diabetologia 2006;49:289-97.

9 Tuomilehto J, Lindström J, Eriksson JG, et al. Prevention of type 2 diabetes mellitus by changes in lifestyle among subjects with impaired glucose tolerance. N Engl J Med 2001;344:1343-50.

10 de Vegt F, Dekker JM, Jager A, et al. Relation of impaired fasting and postload glucose with incident type 2 diabetes in a Dutch population: the Hoorn study. JAMA 2001;285:2109.

11 Engberg S, Vistisen D, Lau C, et al. Progression to impaired glucose regulation and diabetes in the population-based Inter99 study. Diabetes Care 2009;32:606-11.
12 Anjana RM, Shanthi Rani CS, Deepa M, et al. Incidence of diabetes and prediabetes and predictors of progression among Asian Indians: 10-year follow-up of the Chennai urban rural epidemiology study (cures). Diabetes Care 2015;38:1441-8.

13 Valdés S, Botas P, Delgado E, et al. Population-Based incidence of type 2 diabetes in northern Spain: the asturias study. Diabetes Care 2007;30:2258-63.

14 Wang $\mathrm{H}$, Shara NM, Calhoun D, et al. Incidence rates and predictors of diabetes in those with prediabetes: the strong heart study. Diabetes Metab Res Rev 2010;26:378-85.

15 Li G, Zhang P, Wang J, et al. The long-term effect of lifestyle interventions to prevent diabetes in the China dA Qing diabetes prevention study: a 20-year follow-up study. The Lancet 2008;371:1783-9.

$16 \mathrm{Tu}$ JV, Chu A, Rezai MR, et al. The incidence of major cardiovascular events in immigrants to Ontario, Canada: the CANHEART immigrant study. Circulation 2015;132:1549-59.

17 Canadian Diabetes Association. Clinical practice guidelines. Can J Diabetes 2013;37:212.

18 Rezai MR, Maclagan LC, Donovan LR, et al. Classification of Canadian immigrants into visible minority groups using country of birth and mother tongue. Open Med 2013;7:85-93.

19 Shah BR, Chiu M, Amin S, et al. Surname Lists to identify South Asian and Chinese ethnicity from secondary data in Ontario, Canada: a validation study. BMC Med Res Methodol 2010;10:42.

20 Chiu M, Lebenbaum M, Lam K, et al. Describing the linkages of the immigration, refugees and citizenship Canada permanent resident data and vital statistics death registry to Ontario's administrative health database. BMC Med Inform Decis Mak 2016;16:135

21 Lipscombe LL, Hwee J, Webster L, et al. Identifying diabetes cases from administrative data: a population-based validation study. BMC Health Serv Res 2018;18:316.

22 Fine JP, Gray RJ. A proportional hazards model for the Subdistribution of a competing risk. J Am Stat Assoc 1999;94:496-509.

23 Fazli GS, Moineddin R, Bierman AS, et al. Ethnic differences in prediabetes incidence among immigrants to Canada: a populationbased cohort study. BMC Med 2019;17:1-11.

24 Gujral UP, Narayan KMV, Pradeepa RG, et al. Comparing type 2 diabetes, prediabetes, and their associated risk factors in Asian Indians in India and in the U.S.: the CARRS and MASALA studies. Diabetes Care 2015;38:1312-8.

25 Creatore MI, Moineddin R, Booth G, et al. Age- and sex-related prevalence of diabetes mellitus among immigrants to Ontario, Canada. Can Med Assoc J 2010;182:781-9.

26 Booth GL, Creatore MI, Moineddin R, et al. Unwalkable neighborhoods, poverty, and the risk of diabetes among recent immigrants to Canada compared with long-term residents. Diabetes Care 2013;36:302-8.

27 Vang Z, Sigouin J, Flenon A, et al. The healthy immigrant effect in Canada: a systematic review 2015;3:1-41.

28 Kandula NR, Diez-Roux AV, Chan C, et al. Association of acculturation levels and prevalence of diabetes in the multiethnic study of atherosclerosis (MESA). Diabetes Care 2008;31:1621-8.

29 Kennedy S, Kidd MP, McDonald JT, et al. The healthy immigrant effect: patterns and evidence from four countries. J Int Migr Integr 2015;16:317-32

30 Lesser IA, Gasevic D, Lear SA. The association between acculturation and dietary patterns of South Asian immigrants. PLoS One 2014;9:e88495-6.

31 Esposito K, Maiorino MI, Ceriello A, et al. Prevention and control of type 2 diabetes by Mediterranean diet: a systematic review. Diabetes Res Clin Pract 2010;89:97-102.

32 Creatore MI, Booth GL, Manuel DG, et al. Diabetes screening among immigrants: a population-based urban cohort study. Diabetes Care 2012;35:754-61.

33 Lindström J, Absetz P, Hemiö K, et al. Reducing the risk of type 2 diabetes with nutrition and physical activity - efficacy and implementation of lifestyle interventions in Finland. Public Health Nutr 2010;13:993-9.

34 Johnson M, Jones R, Freeman C, et al. Can diabetes prevention programmes be translated effectively into real-world settings and still deliver improved outcomes? A synthesis of evidence. Diabet Med 2013;30:3-15

35 Ackermann RT, Finch EA, Brizendine E, et al. Translating the diabetes prevention program into the community. The DEPLOY pilot study. Am J Prev Med 2008;35:357-63. 